\title{
Hacia una efectiva reparación del daño ambiental: ¿precisión realista $o$ perfeccionismo idealista?*
}

Maria José Alzari** Leonardo de Benedictis*** http://dx.doi.org/10.21503/lex.v9i8.412

* Ponencia presentada en el Primer Congreso Internacional de Medio Ambiente y Derecho Ambiental, los días 26, 27 y 28 de mayo de 2011, en la Universidad Alas Peruanas Filial Chimbote.

** Abogada, especialista en Régimen Jurídico de los Recursos Naturales y en Gestión Ambiental, posgrado en Derecho del Ambiente por la Universidad de Salamanca, y en Políticas e Instrumentos de Gestión Ambiental por la Universidad San Pablo de Madrid.

***Abogado especialista en Derecho Ambiental, con actividades académicas en diversas universidades en cursos de posgrado de la especialidad, miembro de organismos e instituciones especializadas como la Liga Mundial de Abogados Ambientalistas, Instituto de Investigación de Desastres y Emergencias Complejas, y el Instituto de Recursos Naturales, Energía y Ambiente del Colegio de Abogados de Capital Federal de Argentina. 

N adie duda de los efectos que la acción humana esta teniendo sobre el ambiente ni de las consecuencias que el hombre sufre desde este ambiente "afectado". Desastres naturales catastróficos, cambio climático, destrucción de la capa de ozono, degradación de suelos, avance de los desiertos, pérdida de la biodiversidad, contaminación del agua, etc. evidencian una relación de causa-efecto continua, circular: el hombre impacta al ambiente, el ambiente impacta al hombre. Aparecen conceptos como desastre natural, riesgo ambiental, vulnerabilidad ambiental.

Nadie duda, tampoco, acerca de la importancia que el "daño ambiental" tiene tanto desde lo conceptual como desde lo fáctico. O sea, desde cómo se define jurídicamente qué es el daño ambiental y cuáles son las responsabilidades que supone, hasta cuáles son las consecuencias en la salud humana que devienen de un daño ambiental, o qué hacemos ante un daño ambiental, entre muchísimas cuestiones que de un solo concepto aparecen.

Muchas soluciones han aparecido para dar respuesta a este fenómeno. Pero, la situación no parece haber cambiando para positivo, muy por el contrario. Entonces, ¿como encaramos una efectiva reparación del daño ambiental que una actividad humana puede causar?

Justamente, de la definición de "daño ambiental" se derivarán las responsabilidades consecuentes que posibilitarán el remedio para esos daños y la determinación de quienes serán los responsables de dicha solución.

Para lograr esa determinación debemos introducir una cuestión previa. En este sentido, consideramos necesario definir qué se entiende por Derecho Ambiental para lo cual es imprescindible identificar claramente el bien jurídico protegido: el ambiente como bien jurídico.

Sin cuestionamiento, entendemos que el ambiente se encuentra integrado por los recursos naturales (el suelo, el agua, el aire, la flora y fauna, los yacimientos minerales). Ahora, los cuestionamientos aparecen cuando, a los efectos jurídicos, también consideramos incluir 
a las creaciones humanas materiales (edificios, fábricas, caminos, puentes, etc.) e incluso a las inmateriales (música, lenguaje, creencias, instituciones, etc.) en la definición jurídica de "ambiente".

Desde esta última y amplia concepción (bienes de la naturaleza y de las creaciones humanas materiales o inmateriales), llegaríamos a la conclusión de que todo el Derecho es ambiental.

Sin embargo, evidente es que los graves problemas que hoy enfrenta la humanidad en materia ambiental no tienen que ver con alteraciones que estarían sufriendo las creaciones humanas, sino con las alteraciones que está sufriendo la naturaleza. Dicho de otro modo, es el retroceso de los recursos naturales ante el avance de los recursos culturales.

Este debate tiene consecuencia prácticas insoslayables, ya que en definitiva es lo que determinará la eficaz protección del ambiente, finalidad esencial del Derecho Ambiental.

De esta finalidad esencial de protección, se derivan sus consecuencias: una finalidad preventiva (evitar el daño) y otra finalidad de respuesta (reparar el daño y, eventualmente, castigar al causante).

En consecuencia, la extensión y claridad del objeto del Derecho Ambiental aparece como imprescindible en la definición clave del concepto de daño, ya que a partir de esta definición se conocerá qué hay que proteger y, más importante, se sabrá qué hay que evitar.

Debemos hacer una aclaración importante. Cuando hablamos de daño ambiental, nos referimos a los daños de incidencia colectiva causados directamente al ambiente. El daño que se causa en forma particularizada, exclusiva, a determinada o determinadas personas, a través del ambiente, es un daño de incidencia particular que se encuentra regulado por las normas de la responsabilidad civil, específicamente, más allá de la dinámica que el Derecho Ambiental impone en materia procesal principalmente.

Siguiendo con la definición de "daño ambiental", no debemos dejar de tener en cuenta que los bienes de la naturaleza, en general, poseen una capacidad de auto regeneración que no tienen los bienes culturales a los que la denominada "reparación in natura" (reparación que busca volver las cosas al estado anterior al daño) resulta fácilmente aplicable.

Esta capacidad auto regenerativa de los bienes de la naturaleza determina que su "reparación" deba ser considerada teniendo en cuenta aspectos diferentes a los considerados en la "reparación in natura".

Con esto, queremos señalar que un bien cultural necesita, a efectos de su reparación, una acción específica y puntual del hombre. En cambio, un bien natural, por ejemplo el recurso 
aire, ante su contaminación, logrará su reparación y vuelta al estado anterior sin necesidad de desarrollar ninguna tarea de limpieza; solo se necesitará dejar de contaminar y el aire se reparará solo. Algo similar, aunque más lentamente, podría ocurrir ante una contaminación del suelo o de las aguas.

Entonces, debemos preguntarnos si cualquier alteración que se produzca en el ambiente debe ser considerada daño ambiental, o si, por el contrario, es necesario que la misma revista determinada magnitud o caracterización.

Obvio es que la tarea de determinar cuál es la entidad o la gravedad que debe tener el perjuicio ambiental, pues es dificultosa y compleja. Tengamos en cuenta que los bienes o recursos naturales revisten el sustento de nuestra existencia, salud y calidad de vida. Los alteramos y perjudicamos cotidianamente al demandarle alimentos, medicinas, materiales, energía y también recurrir a ellos para que se encarguen de nuestros residuos.

Es por ello que es necesario asumir que nuestra sola presencia genera perjuicios e impactos ambientales negativos. El problema aparece al intentar determinar cuál es el nivel aceptable de estos impactos y perjuicios. No siendo sencillo determinar la línea divisoria entre el impacto ambiental tolerable y el que excede el nivel de tolerancia, por tal motivo se convierte en daño ambiental que debe repararse.

Esta interrogante no es menor, ya que de su respuesta se generarán esas responsabilidades de prevención y de eventual reparación. La pregunta es, ¿̨cualquier alteración del ambiente ingresa en la categoría de daño ambiental?

Siguiendo al Dr. Mario Peña Chacon, podemos empezar con ejemplificar cómo los diferentes marcos normativos han definido el concepto jurídico de daño ambiental.

La ley de Bases Ambiental chilena establece en su artículo segundo que legalmente se debe entender por daño ambiental "toda pérdida, disminución, detrimento, menoscabo significativo inferido al medio ambiente o a uno o más de sus componentes".

En el derecho colombiano, el concepto de daño ecológico comprende aquellos eventos en los que se afecte el normal funcionamiento de los ecosistemas o la renovabilidad de sus recursos y componentes.

Por su parte, la Ley General del Ambiente de Perú define como daño ambiental "todo menoscabo material que sufre el ambiente y/o alguno de sus componentes, que puede ser causado contraviniendo o no disposiciones jurídicas, y que genera efectos negativos actuales o potenciales". 
La Directiva Europea 2004/35/CE sobre "responsabilidad medioambiental en relación con la prevención y reparación de daños medioambientales", define al daño ambiental como "aquel daño que produzca efectos adversos significativos a las especies y habitats protegidos y a las aguas, como asimismo a cualquier contaminación del suelo que suponga un riesgo significativo de que se produzcan efectos adversos para la salud humana”.

En Argentina, a nivel constitucional, el artículo 41 expresa que "el daño ambiental generará prioritariamente la obligación de recomponer según lo establezca la ley”. En consecuencia, la Ley General del Ambiente Nro. 25.675, define daño ambiental como "toda alteración relevante que modifique negativamente el ambiente, sus recursos, el equilibrio de los ecosistemas, o los bienes o valores colectivos" (art. 27); a su vez, el art. 28 consagra la imputación objetiva de responsabilidad al causante de dicho daño con la obligación del restablecimiento del bien protegido al estado anterior a su producción.

O sea que se combina una definición imprecisa de daño ambiental con una responsabilidad objetiva e ilimitada exigiendo una reparación “in natura” respecto de un daño que posee como ya dijimos - capacidad auto regenerativa y respecto del cual muchas veces será imposible la determinación de la extensión de ese volver al estado anterior, sin mencionar, el excesivo costo económico que ello puede suponer, el cual no siempre va a tener igual correlato en un efectivo beneficio ambiental.

Sin lugar a dudas, esta definición amplia, imprecisa, genera una situación de inseguridad jurídica que no beneficia a nadie. Una definición que puede llevar a privilegiar la discrecionalidad de la autoridad (ya sea administrativo o judicial) que, en definitiva, será la que determinará cuándo se está frente a una alteración relevante en los términos de la Ley 25675, incluso ante evidencia técnica-científica internacionalmente reconocida que no avale dicha discrecionalidad. Incluso esta discrecionalidad podría llevar a que el objeto mismo de protección, o sea el ambiente, no se vea beneficiado, siendo la sociedad en su conjunto quien deba responder en virtud del mismo.

Recordemos que definir al daño ambiental implica, por un lado, determinar cuál es el bien jurídico protegido y, por otro, precisar la gravedad de su afectación para calificar como daño y obligar a su reparación.

Es por ello que con el objetivo de hacer posible el desarrollo de actividades productivas responsables con el medio en el cual se llevan a cabo, basadas en criterios de sustentabilidad, resulta indispensable contar con una herramienta efectiva que garantice una satisfactoria reparación de los daños ambientales mediante un régimen legal que, por un lado, confiera mayor precisión a la definición de daño ambiental, con el fin de determinar cuándo el daño 
se configura y cuándo se activa la responsabilidad que obliga a su reparación; y por otro lado, defina el alcance de la "recomposición", en forma expresa, en función de criterios técnicos basados en análisis de riesgo.

Esta propuesta es la solución que el derecho europeo ha encontrado para responder a estos fenómenos. Es así que la Directiva Europea 2004/35/CE define con clara precisión al daño ambiental objeto de protección, contando a su vez con un flexible criterio de reparación de ese daño, admitiendo las acciones correctivas basadas en riesgos.

Estas acciones correctivas basadas en riesgos son normas que determinan niveles límites de concentración de ciertos contaminantes en los recursos naturales. Los límites se obtienen a partir de análisis de riesgo, conducen al establecimiento de una cifra que no implica riesgo cero, sino un riesgo considerado aceptable. De forma tal, claramente y sin temor a discrecionalidades, ante la superación de estos niveles nos contrariamos frente a un daño ambiental a ser reparado.

Encontramos que esta solución a la problemática del daño ambiental es utilizada tanto en la Unión Europea como en EE.UU. de Norteamérica, a efectos de la solución de dicho daño sobre la base de criterios técnicos basados en riesgos.

En definitiva, la tarea sería bajar la contaminación a niveles aceptables de acuerdo a los riesgos, dejando que la naturaleza se encargue del resto. Obviamente, bajar la presencia contaminante hasta niveles aceptables en función del riesgo, no es lo mismo que volver las cosas al estado anterior, que es lo que exige nuestra Ley General del Ambiente.

Las soluciones que se dan en el marco normativo actual en Argentina dejan un amplio margen para las interpretaciones inadecuadas y la aplicación de medidas que quiebren el necesario equilibrio que debe existir entre la preservación ambiental y el crecimiento económico.

Alcanzar los objetivos que el desarrollo sustentable supone, amerita que las sociedades realicen los esfuerzos necesarios para alcanzar un crecimiento tal que permita lograr una calidad de vida digna para sus habitantes, superando los niveles de pobreza que actualmente se registran. Desarrollarse y hacerlo de un modo sustentable que equilibre el crecimiento económico, con la preservación del ambiente y con la equidad social, constituyen un desafío que debe impulsar la búsqueda de soluciones razonables y cumplibles.

Es por ello que no parece sensato abordar una temática tan importante como es la concerniente a los daños ambientales y su reparación a través de imprecisas definiciones en las cuales se establecen determinaciones excesivamente generales y de difícil aplicabilidad, 
puesto que, en más de un caso práctico, la resolución adoptada no tenga nada que ver con el criterio de "recomposición" que se pretende imponer.

Las dificultades que genera la imprecisión, generalidad e irrazonabilidad con que la Ley General del Ambiente aborda la problemática del daño ambiental y las responsabilidades de su reparación, se ven agravadas, incluso, por la imposibilidad de poder dar cumplimiento a la obligación impuesta en el artículo 22 de la Ley en cuestión, referido a la contratación de seguros destinados a garantizar el financiamiento de la recomposición de los daños ambientales. En efecto, es prácticamente imposible encontrar un seguro que cubra un daño de contornos tan imprecisos, como el definido en el artículo 27, unido a una responsabilidad de carácter ilimitado (recomposición del daño) y a una imputación de la misma de carácter objetivo (sin que medie conducta censurable alguna).

Como vimos, la finalidad y, especialmente, el alcance del Derecho Ambiental están ligados, más que al concepto de ambiente, al de daño ambiental. Consecuentemente, no basta con saber qué es lo que debe protegerse, también es necesario saber qué es lo que debe evitarse. Obviamente, si no está claro qué es lo que debe evitarse, lo que implica no tener claro cuál es el impacto ambiental intolerable, será imposible desarrollar un plexo normativo coherente y eficaz. No olvidemos que el principio rector en materia ambiental es el de prevención.

Volviendo a los interrogantes mencionados al principio de este trabajo que apuntaban a dilucidar cuestiones vitales, como la determinación de los elementos que se incluyen en la palabra ambiente o el límite que separa una simple afectación ambiental de un daño que genere consecuencias jurídicas o responsabilidades para quién lo ocasionó, nos lamentamos de no contar en la actualidad con disposiciones legales satisfactorias que permitan que, ante la eventualidad de un daño ambiental, las soluciones sean claras, precisas, y no dependan de la discrecionalidad coyuntural de las diferentes autoridades, que posibilite una acción rápida y responsable de quienes deban reparar ese daño.

Este cuadro de situación, caracterizado por la presencia de concepciones expansivas extremas, ambigüedades e imprecisiones, no pareciera conducirnos hacia un Derecho Ambiental eficaz. Por el contrario, pareciera alentar el desarrollo de un Derecho Ambiental amorfo, integrado por una normativa incoherente e incapaz de dar respuesta satisfactoria a los problemas ambientales que tenemos que enfrentar.

En definitiva, se trata de encontrar soluciones reales a los problemas ambientales que no sean el resultado de un enfrentamiento entre el crecimiento económico y la preservación ambiental, sino que, por el contrario, sean la expresión acabada de un desarrollo sustentable que, para lograr su continuidad en el tiempo, esté fundado en el adecuado equilibrio entre el crecimiento económico, la preservación ambiental y la equidad social. 